\title{
Rainfall estimation techniques over India and adjoining oceanic regions
}

\author{
Anoop Kumar Mishra* and Mohammd Rafiq \\ Centre for Remote Sensing and Geoinformatics, Sathyabama University, Jeppiaar Nagar, Rajiv Gandhi Salai Road, Chennai 600119 India
}

\begin{abstract}
Rainfall estimates have relevance in meteorology, hydrology, agriculture and climate change studies. Near real-time accurate rainfall information at fine spatial and temporal scale is important in the context of occurrence of recent flood events over the Indian region. Poor rain gauge and radar network limit this information over India. Satellites offer an opportunity to measure rainfall over India and the adjoining oceanic region. Available global rainfall products show poor performance for measuring rainfall over a topographically complex region like India. During the past few decades, efforts have been made to improve rainfall estimates over the Indian region. This study aims to provide a broad overview of these advancements, to emphasize on the evaluation of rainfall estimation techniques over India.
\end{abstract}

Keywords: Microwave sensor, rainfall estimation, satellites, visible/infrared observations.

RAINFALL information at various scales is crucial for its applications ranging from flash-flood monitoring to the study of climate study. Unfortunately, rainfall is a difficult parameter to measure due to its highly variable nature. Rain gauges measure rainfall at a specific point, which can be extrapolated (temporally and spatially) to the nearby area but with questionable accuracy, especially over complex topographical regions like India. Radar offers an improved rainfall monitoring option. However, the radar network over India is poor ${ }^{1}$. Meteorological satellites provide a unique opportunity to monitor rainfall over India, which lacks calibrated weather radar and good rain gauge density. The advancements in satellite-based rainfall measurement techniques have registered tremendous progress and realistic achievements over the past decades ${ }^{2}$. Advantage of meteorological satellites for rainfall monitoring is partially offset by their evident limitation, namely the indirect relationship between variables directly measured from space and surface rainfall. Despite this limitation, meteorological satellites present the best tool to monitor rainfall. In a developing country like India, where rainfall is crucial to everyday life, an effective monitoring technique is essential. Satellite-based observations have the potential to overcome spatio-temporal inconsistencies of ground-based rain

*For correspondence. (e-mail: daksha112@gmail.com) gauge and radar observations. Geo-stationary satellites, limited to visible (VIS) and infrared (IR) wavelengths are essential for rainfall observations due to continuous monitoring of cloud systems. However, VIS observations of rain systems are not available during night-time. Rainfall estimates based on IR measurements show large errors due to indirect relationship between surface rain and cloud-top temperature. However, microwave radiation is able to penetrate through the clouds for direct interaction with rain storms. Unfortunately, microwave measurements suffer from poor spatial and temporal samplings. Alternatively, accurate microwave measurements can be combined with continuous IR observations to provide global rainfall measurements.

Numerous satellite rainfall products are available using IR, microwave and combined observations. These datasets merge different estimates of rainfall from different sensors and satellites into a rainfall product. Few of these rainfall products are the Tropical Rainfall Measuring Mission (TRMM) Multi-satellite Precipitation Analysis (TMPA) near real-time product ${ }^{3}$, the Global Satellite Mapping of Precipitation (GSMaP) ${ }^{4}$, Climate Prediction Centre MORPHing (CMORPH $)^{5}$, Precipitation Estimation from Remote Sensing Information using Artificial Neural Network (PERSIANN) ${ }^{6}$, hydro-estimator $(\mathrm{H}-\mathrm{E})^{7}$ and Integrated Multi-satellitE Retrievals for GPM (IMERG) $^{8}$. Previous studies have reported that these products show large disagreement with ground truth over India ${ }^{1,9,10}$. Poor performance of global rainfall products over India may be due to the fact they are based on rainfall signatures derived for the globe and these signatures do not represent rainfall over topographically complex regions like India. It has been reported that regional rainfall signatures derived specifically for the Indian region outperform global rainfall signatures for their application in rainfall monitoring ${ }^{11}$. This explains the requirement of regional rainfall estimation technique over the Indian region. The present article aims to provide a broad overview of rainfall estimation techniques over India, to emphasize on the evaluation these techniques over the region.

\section{Rainfall estimation using visible/infrared observations}

VIS and IR imagers from geo-stationary weather satellites continuously monitor the growth and decay of 
precipitating clouds. Hydrometeor observations in VIS and IR images obtained from satellites are often used to measure rainfall rates over remote areas. Relationship between the cloud-top brightness temperature and surface rainfall was used in various empirical techniques for measuring rainfall ${ }^{12}$. The Global Atmospheric Research Program (GARP) Atlantic Tropical Experiment (GATE) data was used by Arkin ${ }^{13}$ to find good agreement between areal coverage of cold cloud and six-hourly rainfall. Arkin $^{13}$ reported that this agreement improved with increasing spatial and temporal averaging scales up to $2.5^{\circ}$ and $24 \mathrm{~h}$. This observation suggested a linear relationship between rainy cloud coverage area and climatic-scale rainfall over study area. Arkin and Meisner ${ }^{14}$ used this observation to propose the GOES Precipitation Index (GPI) as rainfall estimation technique over tropical oceans. The GPI is calculated from the product of mean fractional coverage of cloud colder that $235 \mathrm{~K}$ in a $2.5^{\circ} \times 2.5^{\circ}$ box. A constant rain rate of $3 \mathrm{~mm} / \mathrm{h}$ was assigned for a rainy cloud pixel with brightness temperature less than a threshold. Arkin et al. ${ }^{15}$ used this technique to monitor rainfall on weekly and monthly temporal scale at $2.5^{\circ} \times 2.5^{\circ}$ grid box over India using IR observations of INSAT-1B.

The fractional cloud coverage within a $2.5^{\circ} \times 2.5^{\circ}$ grid box was calculated as the ratio of pixels colder than $235 \mathrm{~K}$ to the total pixels. Rainfall was calculated using the equation

$$
R_{\mathrm{GPI}}=3 F \Delta T \text {, }
$$

where $R_{\mathrm{GPI}}$ is the rainfall estimated using GPI technique; $F$ the fractional cloud coverage with cloud-top temperature $\leq 235 \mathrm{~K}$ for the prescribed $1^{\circ} \times 1^{\circ}$ grid box and $\Delta T$ represents integration time.

Arkin et al. ${ }^{15}$ reported that threshold of $235 \mathrm{~K}$ resulted in good accuracy over the entire region except orographic region (along the west coast) where a threshold of $265 \mathrm{~K}$ provided accurate estimates. Rao et al. ${ }^{16}$ and Bhandari and Varma ${ }^{17}$ also used INSAT-1B data to monitor rainfall over India using the approach developed by Arkin et al. ${ }^{15}$. Performance of rainfall estimates from Arkin et al. ${ }^{15}$ was tested by Roy Bhowmik and $\mathrm{Sud}^{18}$, who reported an underestimation in heavy rainfall over major regions of Indian summer monsoon. This underestimation was attributed to the fact that rainfall rate constant $(72 \mathrm{~mm} /$ day $)$ was unrealistically low, especially in the case of deep convective rainy systems associated with Indian summer monsoon. Nath et al. ${ }^{19}$ devised an improved rainfall estimation technique using artificial neural network (ANN) to India Meteorology Department Quantitative Precipitation Estimates (IMD QPE). It may be noted that IMD QPE rainfall estimates are based on Arkin et al. ${ }^{15}$. Nath et al. ${ }^{19}$ used ANN to post-process the satellite estimates based on their error characteristics and improved IMD QPE estimates. Their technique was based on two phases.
The first phase utilized IMD QPE and observed rainfall fields to quantify statistics, while the second phase took into consideration IMD QPE and derived statistics to acquire the modified IMD QPE. Nath et al. ${ }^{19}$ reported that ANN-based improved rainfall technique was able to provide better results compared to IMD QPE. GPI technique was also used to monitor rainfall during southwest (SW) monsoon season in India from Kalpana data ${ }^{20}$. It was reported that GPI technique was capable of capturing broad-scale monsoon rainfall features over India. Largescale rainfall features were studied by Prakash et al..$^{21}$ using GPI technique during SW monsoon period in India. They used Kalpana-1 satellite IR observations to estimate rainfall at $1^{\circ} \times 1^{\circ}$ grid box. Validation of results with standard merged satellite product, namely Global Precipitation Climatology Project (GPCP) and rain gauge-based product, namely Global Precipitation Climatology Centre (GPCC) showed that rainfall estimated using GPI technique captured the active and break spells of monsoon very well. They reported that GPI technique can be utilized to monitor rainfall over India at a larger temporal scale for application in climate studies. Mishra et al. $^{22}$ modified the existing GPI technique to refine refining its application from larger climatic scales to shorter scale for daily rainfall measurement. It may be observed that rainfall is overestimated in conditions and underestimated in moist conditions because the falling raindrops evaporate before reaching the surface under dry conditions. Furthermore, they tend to grow in size in moist conditions ${ }^{23}$. It can be concluded that water vapour content below the clouds in the atmosphere affects rain measurement using GPI technique. Mishra et al. ${ }^{22}$ developed a Modified GPI (MGPI) technique by adopting the approach of Vicente et $a l{ }^{23}$ to reduce the errors in rainfall estimates subject to the absence or presence of water vapour in the underlying atmosphere. They used IR observations of Very High Resolution Radiometer (VHRR) from Kalpana by applying environmental moisture correction factor through the presence of water vapour to GPI technique for improving rainfall measurement for its application at finer scale. Environmental moisture correction factor was derived using six-hourly forecast data of atmospheric column relative humidity and precipitable water from model forecast from the National Centers for Environmental Prediction-Global Forecast System (NCEP-GFS) available at $1^{\circ} \times 1^{\circ}$ grid .

Rainfall is estimated by MGPI technique using the following two steps: (i) By calculating rainfall using GPI approach and (ii) applying the environmental moisture correction factor in the rainfall measurements derived in the first step. Mishra et al. ${ }^{22}$ utilized Kalpana IR images (available at $8 \mathrm{~km}$ spatial resolution) at each synoptic hour. The fractional cloud coverage within a $1^{\circ} \times 1^{\circ}$ grid box was derived as the ratio of pixels colder than $235 \mathrm{~K}$ to the total pixels. For the first step, rainfall was calculated using eq. (1). 

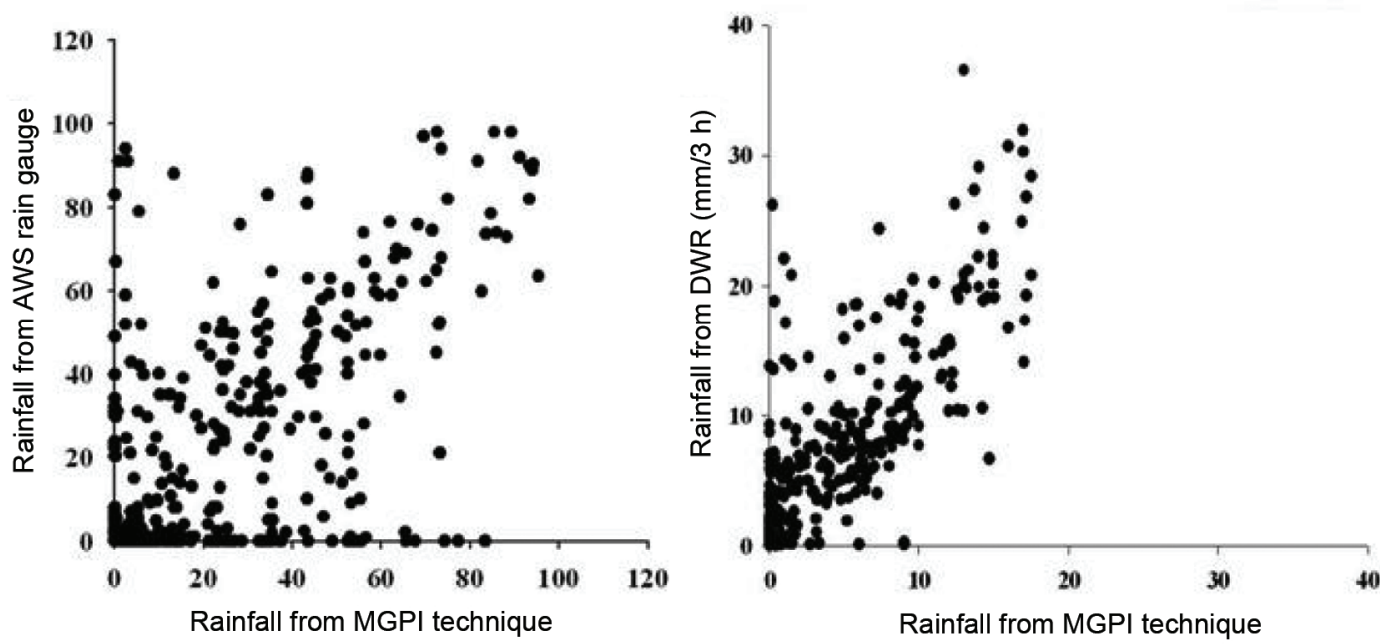

Figure 1. Validation of rainfall estimated using MGPI technique with that using rain gauges (at $24 \mathrm{~h}$ resolution) and DWR (at 3 h resolution) (from Mishra et al. ${ }^{11}$; courtesy: ELSEVIER).

For the second step, environmental moisture correction factor (PWRH) was calculated by multiplying precipitable water integrated from the surface to $500 \mathrm{mb}$ with relative humidity (integrated value from surface to $500 \mathrm{mb}$ level) using NCEP-GFS data at six-hourly temporal resolution. Precipitable water was converted to inches. The values of the PWRH were found to be between 0 and 2; the environment is treated as dry if PWRH is below 1.0 and quite moist if PWRH exceeds 1.0. Final rainfall ( $\left.R_{\mathrm{MGPI}}\right)$ was calculated by multiplying $R_{\mathrm{GPI}}$ with PWRH as follows

$$
R_{\mathrm{MGPI}}=R_{\mathrm{GPI}} \times \mathrm{PWRH}
$$

The performance of MGPI technique was compared and tested for the SW monsoon season with ground-based observations. It was also validated against ground-based rain gauge observations from Indian Space Research Organisation (ISRO). For validation with rain gauges, Mishra et $a .^{22}$ used 1245 data points from multiple rainy spells of monsoon, pre-monsoon and post-monsoon in 2007. A correlation coefficient (CC) of 0.6022 and root mean square error (RMSE) of $23.84 \mathrm{~mm}$ were reported against rain gauge observations, indicating good performance of the MGPI technique. They also validated rainfall observations from MGPI technique with those from DWR data by considering 542 data points during rainy spells of 2007 and 2008. A CC of 0.69, RMSE of $3.15 \mathrm{~mm}$ and bias of $1.41 \mathrm{~mm}$ were reported (shown in Figure 1). These results showed the capability of MGPI technique to retrieve rainfall with reasonable accuracy. MGPI technique using Kalpana-IR data is suitable for measuring near real-time rainfall over India and nearby regions. However, this technique underestimates heavy rainfall over the regions of orographic activities. Cirrus cloud, a non-rainy cloud, filters in as a rainy cloud in this approach too and thus is a source of error. This rainfall product is operational at Space Applications Centre, ISRO, Ahmedabad.

Singh and Singh $^{24}$ also used Kalpana IR channel to estimate seasonal rainfall over India. Gairola et al. ${ }^{25}$ also validated the MGPI technique ${ }^{22}$ and found that underestimation of rainfall by GPI technique was significantly improved by the MGPI technique.

Long-term record of IR and VIS observations from INSAT-1B launched in 1983 to recent geostationary satellites, viz. INSAT-3D launched in 2013 and INSAT3DR launched in 2016, offers a unique opportunity to monitor rainfall for climatological applications over India.

\section{Rainfall estimation using microwave observations}

Rainfall information from the IR and VIS observations is inferred indirectly from the cloud top. IR and VIS radiations do not penetrate through clouds and thus cannot interact with cloud droplets, which may result in significant errors in rainfall measurement. Results show that rainfall from IR and VIS observations is overestimated due to the presence of high cirrus or anvil clouds appearing in the field of view ${ }^{1,11,22}$. On the other hand, microwaves are less affected by clouds and they directly interact with cloud droplets which makes microwave sensors more suitable for rainfall estimation compared to IR and VIS sensors ${ }^{26-33}$. Additionally, microwaves are largely insensitive to the presence of ice in thin cirrus clouds. The last few decades witnessed a revolution in satellite microwave remote sensing for better measurement of rainfall with the launch of satellites such as TRMM, IndoFrench mission Megha-Tropies, Global Precipitation 
Mission (GPM), etc. Microwave radiometers on-board polar satellites have been used to monitor rainfall since the past few decades. Gairola et al. ${ }^{2}$ summarized the various approaches to monitor rainfall using microwave observations. Emission and scattering theories are widely utilized to monitor rainfall from microwave observations ${ }^{32-34}$. Emission theory utilizes emitted radiations from hydrometeors to quantify rainfall estimates. These emitted radiations are affected by surface emissivity and thus emission-based technique is applicable to oceanic background due to low and homogeneous sea-surface emissivity. Emissivity at a particular frequency, polarization and incidence angle may depend on factors such as index of refraction, surface roughness induced by wind, sea surface temperature and salinity. Wilheit ${ }^{35}$ used radiative transfer model to compute ocean emissivity as a function of near-surface wind speed. Emissivity depends mainly on soil moisture and the type of soil and vegetation over land region.

Scattering-based theory is used to monitor rainfall by observing the depression in microwave radiation due to scattering by hydrometeors. Rainfall signatures from hydrometeors become complicated by high and inhomogeneous emissivity of land. Rainfall estimation over land is more complicated compared to that over ocean due to high variability of emissivity over land cover. Emission signature from liquid water contents in the atmosphere gets blocked by high emissivity. Thus brightness temperature depression only due to scattering from the upper cloud layer is readily observed. Rain layer extends above the freezing level, and as such, contains a mixture of water and ice particles for most of the rain systems. Size and density of the ice particles from these rainy systems vary depending upon the cloud microphysics and dynamical forcing. SSM/I observations at 37 and $85 \mathrm{GHz}$ were used to report a significant depression in brightness temperature due to scattering from bigger ice particles ${ }^{36}$. Scattering index is the measurement of depression in brightness temperature due to ice scattering from hydrometeors above freezing level. It is dependent on the presence of ice particles in the rain system above freezing level (or layers of the clouds). Information regarding the cloud base is not required for deriving rain rate from scattering index. Rain rate can be derived from scattering index using a nonlinear power law equation established between them from a large database of collocated observations from surface rainfall and scattering index.

The retrieval process is further complicated due to lack of consistent background against which depression in brightness temperature can be compared. A rain/no-rain threshold is required to minimize the problem due to inhomogeneous emissivity resulting from a change in surface characteristics and temperature variability. Background emissivity is quasi-static and remains low over oceanic region, thus resulting in low brightness temperature. However, emissivity from hydrometeors leads to an increase in brightness temperature. This allows us to differentiate between rainy systems (based on signature of high brightness temperature) and non-rainy systems (low brightness temperature) over oceanic background. Due to scattering effect, a depression in brightness temperature is measured, which can be utilized for rainfall estimation.

Using observations at $85 \mathrm{GHz}$ channel from SSM/I data, a global scattering index was derived ${ }^{27}$. Ferraro and Marks $^{36}$ refined this technique using multiple frequency observations from SSM/I data. Due to variable nature of scattering index, errors were introduced. Ferraro and Marks ${ }^{36}$ collocated rainfall from radar data against scattering index derived from SSM/I observations. They found tremendous scatter in rainfall rate and scattering index. Despite this they found that there was an increase in rain rate with increase in scattering index. To derive a relationship between rain rate and scattering index, radar data were binned in $1 \mathrm{~mm} / \mathrm{h}$ rain rate and scattering index in these bins was averaged ${ }^{36}$. This resulted in improvement of the statistical relationship between scattering index and rain rate.

It was found that scattering index was highly variable with regions and seasons, and showed large errors over the Indian region ${ }^{11}$. A regional scattering index was developed by Mishra et al. ${ }^{11}$ for rainfall measurement over India and adjoining oceanic region using SSM/I data at 19, 22 and $85 \mathrm{GHz}$ channels. These regional indices were used as rainfall signature and collocated against rainfall from precipitation radar (PR) of TRMM for developing a rainfall estimation technique over India. Rainfall estimation using this technique consists of two steps and is described as follows: Regional scattering index over India is derived using observations from 19, 22 and $85 \mathrm{GHz}$ channels separately for land and oceanic region as a first step. In the second step, the scattering index is converted into rainfall from PR using nonlinear regression approach.

The following relationship between 19, 22 and $85 \mathrm{GHz}$ channels was established during non-rainy events to derive scattering index

$$
F=a+\left(b \times \mathrm{Tb}_{19 \mathrm{~V}}\right)+\left(c \times \mathrm{Tb}_{22 \mathrm{~V}}\right)+\left(d \times\left(\mathrm{Tb}_{22 \mathrm{~V}}\right)^{2}\right),
$$

where $F$ represents $85 \mathrm{GHz}$ channel brightness temperature for non-rainy events and $\mathrm{Tb}_{19 \mathrm{v}}$ refers to vertically polarized brightness temperature $(\mathrm{K})$ at frequency $f$ measured.

Coefficients $a, b, c$ and $d$ were calculated using a large dataset (4671 data points over land and 3974 points over oceanic region) from SSM/I F-13 over India and adjoining ocean. The following coefficients were estimated for land with standard error of estimates as 1.351 using regression analysis

$$
a=448.68, b=-1.545, c=-0.6020 \text { and } d=0.0055 \text {. }
$$



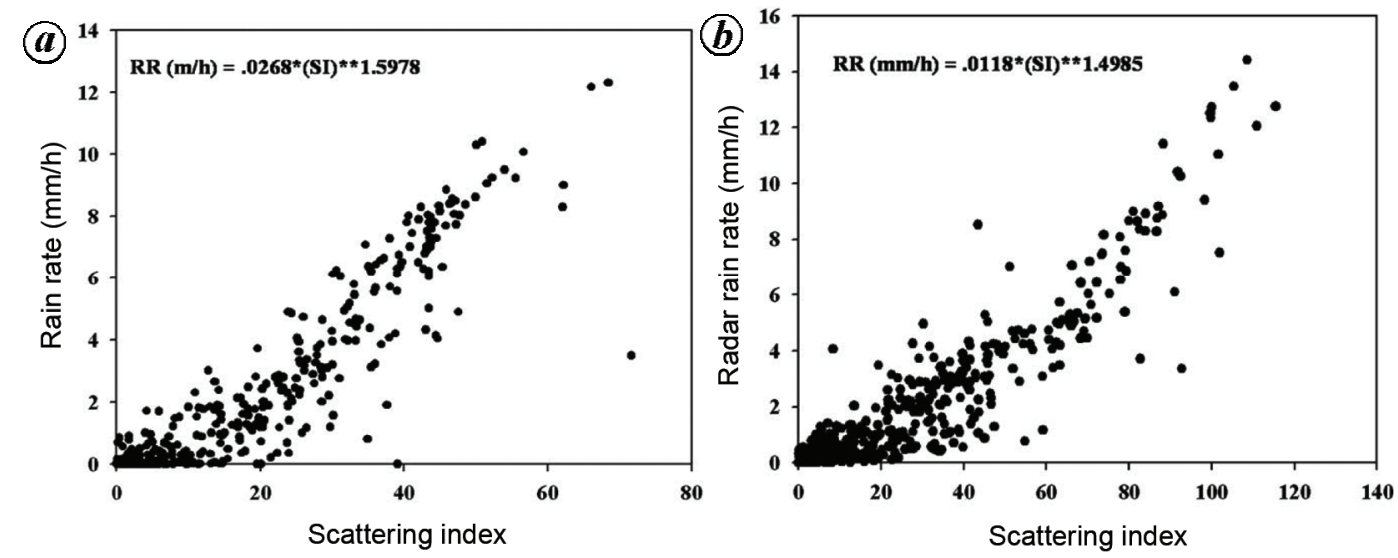

Figure 2. Nonlinear relationship between regional scattering index from SSM/I and rainfall from PR over (a) land and (b) ocean (from Mishra et al. ${ }^{33}$; courtesy: ELSEVIER).

On the other hand, the following coefficients were derived for oceanic region with standard error of estimates as 1.826

$$
a=-362.44, b=1.138, c=3.525 \text { and } d=-0.0078 \text {. }
$$

The value of $F$ was calculated using eq. (3) and derived coefficients. Scattering index (SI) was derived from the following equation

$$
\mathrm{SI}_{85}=\mathrm{F}-\mathrm{Tb}_{85 \mathrm{~V}}
$$

It may be noted that the value of SI must be zero for nonrainy conditions. So, this index can also be used to distinguish between scattering and non-scattering signals.

The scattering index was calibrated with rainfall from PR over land and ocean separately, using large data base of collocated observations (Figure 2).

Various linear and nonlinear regressions were used to relate scattering index with rainfall, but power law relationship outperformed other regressions. Using power law regression analysis, the following two relationships were derived for land (with standard error of estimates being $1.138 \mathrm{~mm} / \mathrm{h}$ ) and oceanic region (with standard error of estimates being $0.9097 \mathrm{~mm} / \mathrm{h}$ )

$$
\begin{aligned}
& \mathrm{RR}_{\text {land }}=0.0268 \times\left(\mathrm{SI}_{85}\right)^{1.5978,} \\
& \text { RRocean }=0.0118 \times\left(\mathrm{SI}_{85}\right)^{1.4985},
\end{aligned}
$$

where $R R_{\text {land }}$ and $R R_{\text {ocean }}$ are rain rates $(\mathrm{mm} / \mathrm{h})$ over land and ocean respectively.

Equations (5) and (6) are used to monitor rainfall over land and ocean separately.

It can be observed that regional scattering index-based algorithm is able to efficiently capture monsoon depression over the Indian region. Performance of this technique was validated against ground-based ISRO rain gauge and DWR observations.
For this, the AWS observations falling within regional scattering rainfall technique grid $\left(0.5^{\circ} \times 0.5^{\circ}\right)$ were averaged and then compared. Figure $3 a$ shows validation of result with rain gauge.

A CC of 0.68, RMSE of $9.35 \mathrm{~mm} / \mathrm{h}$ and bias of $-3.64 \mathrm{~mm} / \mathrm{h}$ were reported from the validation using data from 2007 and 2008. Figure $3 b$ shows validation of results with DWR observations.

Statistical results showed a CC of 0.69 , RMSE of $3.12 \mathrm{~mm} / \mathrm{h}$, bias of $-1.18 \mathrm{~mm} / \mathrm{h}$, probability of detection (POD) of 0.81 , false alarm ratio (FAR) of 0.21 and a skill score of 0.36 with DWR data. These validation results presented in Figure $3 a$ over the Indian region confirmed the importance of the regional scattering index-based rainfall estimation technique to monitor rainfall accurately.

Mishra $^{33}$ developed a technique using TRMM Microwave Imager (TMI) data to monitor heavy rainfall by application of multiple rain signatures and utilizing both linear and nonlinear regression techniques. These signatures include SI, polarization corrected temperature (PCT) and their combinations. Spencer et al. ${ }^{26}$ derived PCT using both polarization and scattering features of microwaves at $85 \mathrm{GHz}$ scattering channel. It may be noted that large areas of very low emissivity regimes exhibit false rain signatures due to the presence of low brightness temperature in the vicinity of cold sea surface region in the high-frequency ice scattering channels. PCT derived by Spencer et $a .^{26}$ can be used to delineate the surface effects. PCT is useful to monitor rainfall because it is highly insensitive to the underlying surface (land or water). Thus, high-frequency PCT responds exclusively to the ice scattering signature. PCT can be derived at other scattering channels (37 and $157 \mathrm{GHz}$ ) also. However, PCT at $85 \mathrm{GHz}$ channel is used frequently because missions like TRMM, SSM/I, Megha-Tropiques and GPM have this channel in common.

It was observed that both PCT and vertically polarized brightness temperature are flat at $37 \mathrm{GHz}$ (ref. 37). PCT at $85 \mathrm{GHz}$ was used to explore precipitation features over 

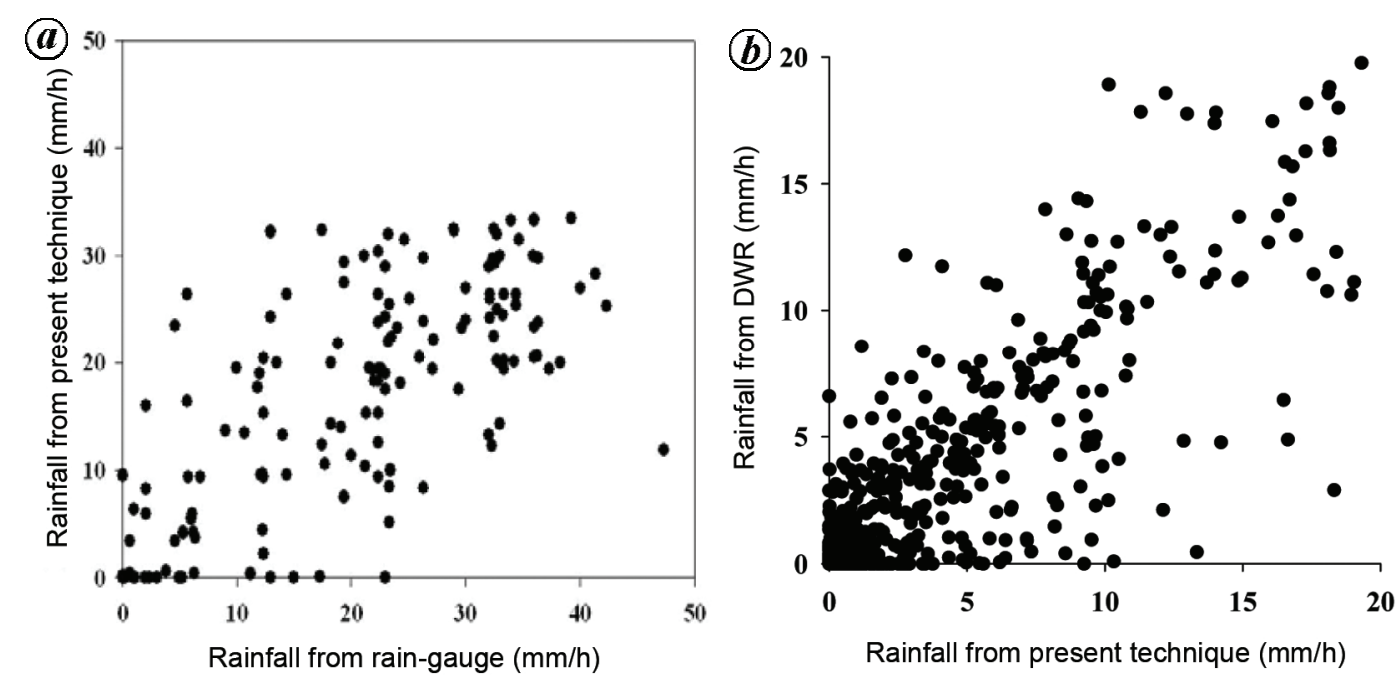

Figure 3. Scatter plot between rainfall from regional scattering index scheme and that from (a) AWS rain gauge (from Mishra et al. $^{33}$; courtesy: ELSEVIER) and (b) DWR observations.

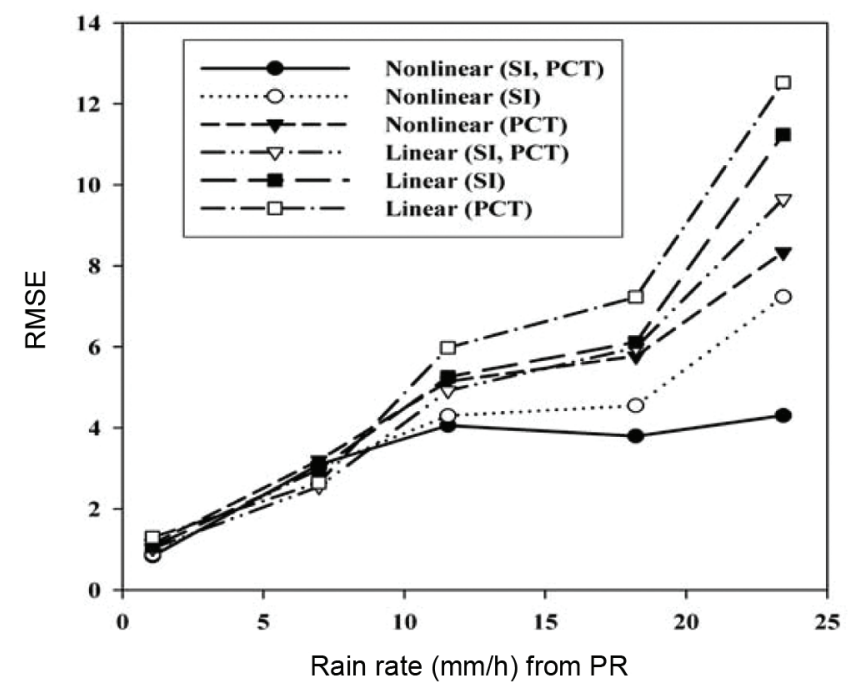

Figure 4. RMSE at different rainfall ranges from both linear and nonlinear regression analysis using various signatures and their sets (from Mishra ${ }^{34}$; courtesy: Springer).

India employing SSM/I data by Kumar et $a l .{ }^{38}$ using the equation

$$
\mathrm{PCT}=(1+a) \mathrm{Tb}_{85 \mathrm{~V}}-a \mathrm{~Tb}_{85 \mathrm{H}}
$$

Value of $a$ was set as 0.818 for keeping the values of PCT as constant when there was no precipitation. Equation (7) is valid for both land and ocean. Regression analysis was performed using data from PR rainfall and SI, PCT, and a combination of SI and PCT during cyclonic events of 2007, 2008, 2009, 2010 and 2011 using both linear and nonlinear regression analysis. Results showed that the technique based on linear regression could not capture heavy rainfall events. Single rain signatures (SI or PCT) could not retrieve rainfall with good accuracy. Figure 4 shows validation of results with independent PR observations.

The figure indicates that performances of these techniques are almost similar in measuring low rainfall events (up to $10 \mathrm{~mm} / \mathrm{h}$ ). Thus nonlinear regression technique using a combination of SI and PCT shows better performance compared to other combinations for measuring heavy rainfall events.

Gohil et $a l^{39}$ derived regional scattering index following the approach adopted by Mishra et $a l^{32}$ for monitoring rainfall from Megha-Tropiques observations. Balaji et $a l{ }^{40}$ described an ANN approach to estimate rainfall over India using simulated brightness temperatures corresponding to SAPHIR frequencies of Megha-Tropiques. They reported that heavy rainfall associated with cyclonic events can be retrieved accurately using ANN.

Thus, high-frequency ice scattering channels available from recent GPM mission will be helpful in improving rainfall estimates over India and adjoining oceanic region.

\section{Rainfall estimation using integrated infrared and microwave observations}

As discussed above, both IR and microwave-based rainfall estimation techniques have their advantages and limitations. The development of integrated techniques using the strengths of both microwaves and IR radiation is therefore highly advantageous. Over the past few decades, efforts have been made to integrate IR observation with microwave estimates, wherein the advantage of global coverage and near sufficient space-time sampling of IR observation and accuracy of microwave measurement are used ${ }^{1,9,32,41,42}$. Mitra et al. made first attempt to 
merge rain gauge observations with satellite based INSAT-QPE estimates to monitor rainfall over Indian region. Several attempts have been made to monitor rainfall over India by combining rain gauge data with INSATbased rainfall estimates ${ }^{43-46}$. Rain-gauge observations were integrated with near real-time TRMM-based rainfall measurements to estimate rainfall over India ${ }^{47}$. Rainfall estimates obtained from this integrated approach are operational at IMD for monitoring rainfall. A technique was proposed to estimate heavy rainfall by merging IR observations from Kalpana with near-surface rainfall from PR observations $^{32}$. Gairola et al. ${ }^{47}$ proposed an algorithm, viz. the Indian National Satellite System (INSAT) Multispectral Rainfall Algorithm (IMSRA), for estimating rainfall over India and adjoining oceanic region by merging Kalpana IR observations with those from PR estimates. Usefulness of this algorithm was explored for its application to monitor SW monsoon seasons of 2008 and 2009 at daily and monthly scales using rain-gauge observations $^{48}$. It was reported that the IMSRA technique efficiently captures all the synoptic features of the Indian summer monsoon. It was also found that IMSRA substantially underestimates rainfall over orographic regions, including the west coast of India and foothills of the Himalaya. Performance of IMSRA technique was tested over the Indian region with Kalpana-1 GPI and TRMM Multisatellite Precipitation Analysis (TMPA) estimates ${ }^{49}$. It was reported that IMSRA measurements are closer to the TMPA estimates and are capable of estimating rainfall at smaller scales. IMSRA algorithm is operational at IMD for various applications, including agriculture and hydro-meteorology ${ }^{50}$. Rainfall estimates over India were improved by merging rain-gauge observations with Kalpana-based IMSRA rainfall estimates in a previous study ${ }^{51}$.

Mishra et al. ${ }^{1}$ used active microwave observations from PR to develop a new algorithm. Detailed information regarding the rain systems is provided by $P R$ at $5 \mathrm{~km}$ spatial resolution. Mishra et al. ${ }^{1}$ utilized measurements in IR and water vapour (WV) channels from geostationary satellite Meteosat-7 to classify clouds into various categories, including low-level clouds, thin cirrus, convective and deep convective clouds using a scheme adopted and devised by Roca Remy et al. ${ }^{52}$. This classification scheme allows delineation of non-rainy cirrus clouds, which is one of the major sources of error in IR-based rainfallmeasuring algorithm. Convective and deep convective clouds were identified using this scheme. As discussed earlier, rainfall is a highly variable quantity and its accurate information within a specific grid box is dependent on effective screening of non-raining pixels. Observations in IR channel alone cannot provide accurate estimates of rainfall because it gives information regarding cloud tops only. Barret and Martin ${ }^{53}$ used multispectral observations for exploring structural analyses of hydrometeors to effectively locate rainy areas.
Mishra et al. ${ }^{1}$ adopted the scheme suggested by Roca Remy et al. ${ }^{52}$ to classify clouds using measurements at IR and WV channels of Meteosat-7 data. This scheme was based on simple thresholds to classify various cloud classes. The pixels were classified as clear sky (and thus were not selected for collocation) if brightness temperature in the IR channel $\left(\mathrm{Tb}_{\mathrm{IR}}\right) \geq 282 \mathrm{~K}$ and standard deviation of $\mathrm{Tb}_{\mathrm{IR}}$ of neighbouring pixels was $\leq 0.5 \mathrm{~K}$. Pixels were classified as mid- to upper-level clouds if $\mathrm{Tb}_{\mathrm{IR}} \leq 270 \mathrm{~K}$ and were selected for collocation. Pixels were classified as thin cirrus (and thus screened out) if $\mathrm{Tb}_{\mathrm{IR}} \geq 270 \mathrm{~K}$ and $\mathrm{Tb}_{\mathrm{WV}} \leq 246 \mathrm{~K}$. $\mathrm{Tb}_{\mathrm{IR}}$ from Meteosat was collocated against rainfall from PR within 15 min of time difference, in which the autocovariance function of rainfall reduces to about 0.65 (ref. 54). Nonuniformity was not considered at finer scale because $\mathrm{PR}$ and $\mathrm{Tb} \mathrm{b}_{\mathrm{IR}}$ have the same resolution. Also, 11,875 data points during heavy rainy spells of 2006 and 2007 were selected over India and nearby oceanic region to collocate measurements of $\mathrm{PR}$ rainfall and $\mathrm{Tb}_{\mathrm{IR}}$ at $0.25^{\circ} \times 0.25^{\circ}$ grid box (Figure 5). Nonlinear regression analysis was performed and the following relation was established between rainfall and brightness temperature

$$
\mathrm{RR}_{\text {merged }}=16.66 \times \exp \left(-\left(\mathrm{Tb}_{\mathrm{IR}}-204.57\right) / 16.53\right) \text {. }
$$

Equation (8) also confirms logarithmic relationship between these variables as reported by previous stu$\operatorname{dies}^{23,55}$.

Rainfall was estimated using eq. (8) over India and nearby oceanic region. The developed technique was used to estimate rainfall over India during contrasting rain events. It was applied to study rainfall during severe

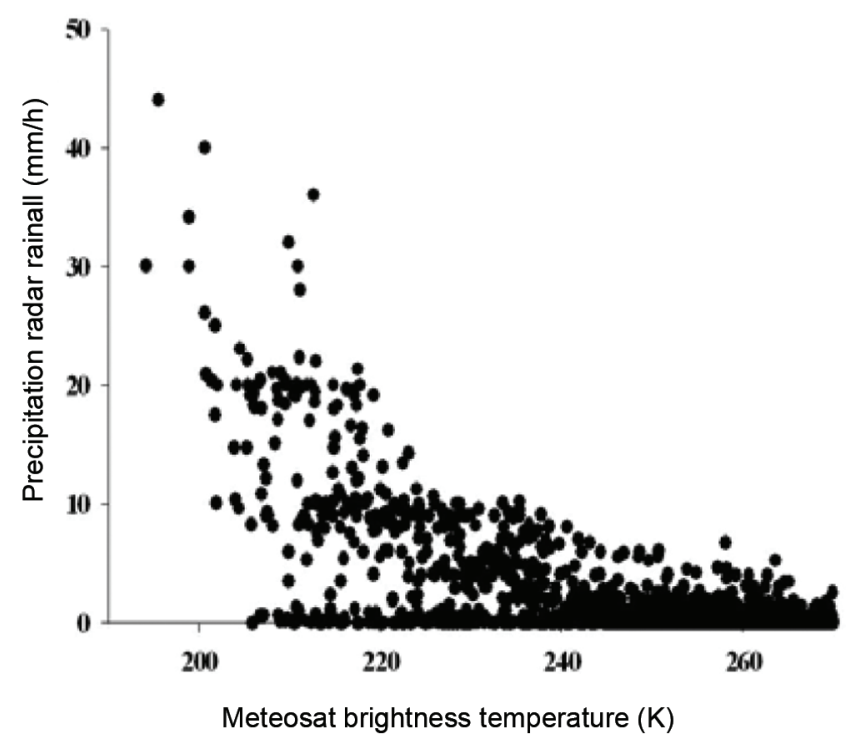

Figure 5. Scatter plot between brightness temperature from Meteosat and rain rate from PR ( $x$-axis: Meteosat brightness temperature $(\mathrm{K})$ and $y$-axis: precipitation radar rainfall $(\mathrm{mm})$. (From Mishra et al. ${ }^{1}$; courtesy: AGU). 
(a)

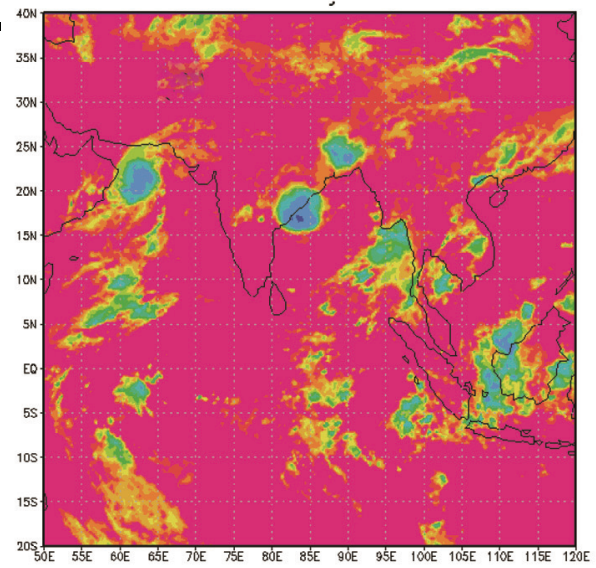

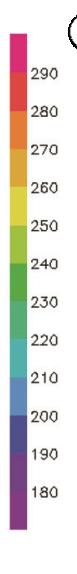

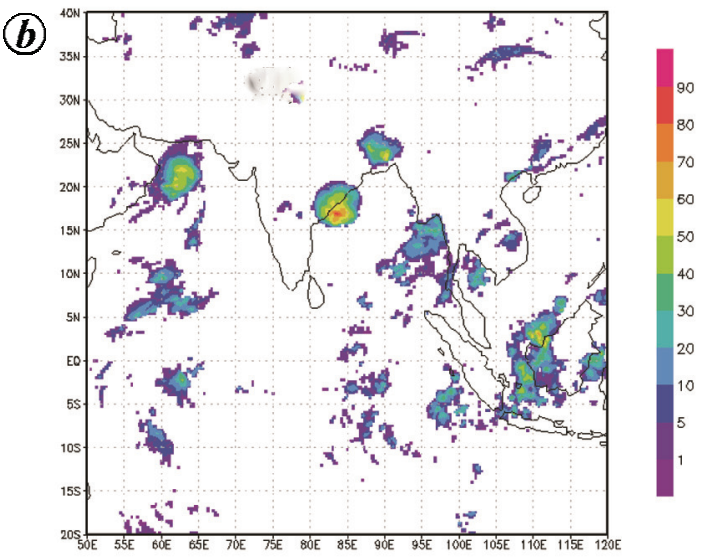

Figure 6. Spatial coverage of (a) brightness temperature $(\mathrm{K})$ and $(\boldsymbol{b})$ rainfall $(\mathrm{mm} / 3 \mathrm{~h})$, on 5 June 2007 at 0300 UTC (from Mishra et al. ${ }^{1}$; courtesy: AGU).

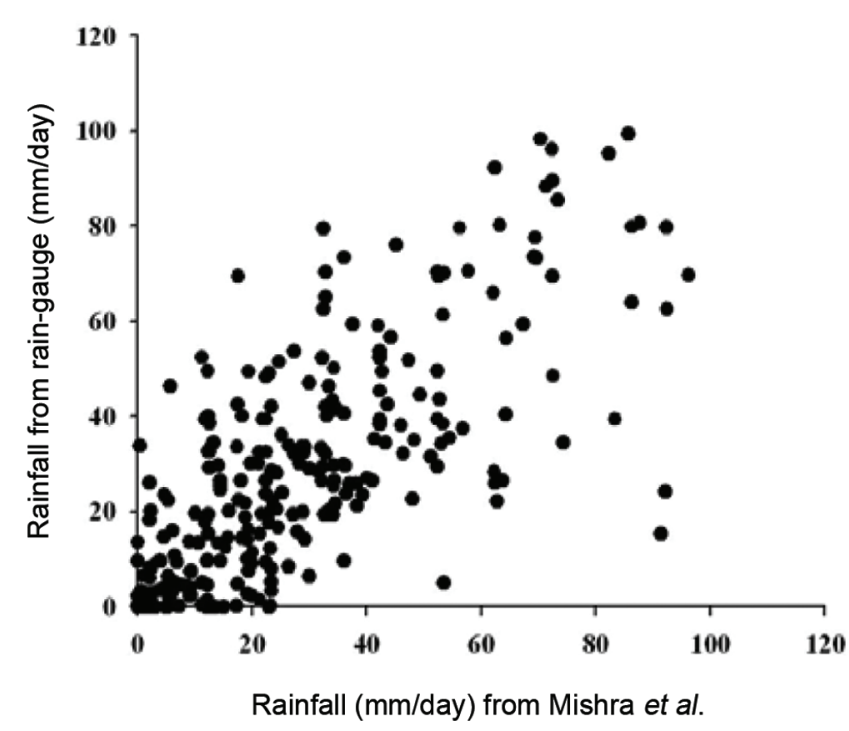

Figure 7. Scatter plot between rainfall estimated by Mishra et al. ${ }^{1}$ and using AWS rain gauge for S-W monsoon period (from Mishra et al. ${ }^{1}$; courtesy: JGR-AGU).

cyclone Gonu, which formed into the Gulf of Oman on 5 June 2007 at 0300 UTC (Figure 6).

There were three heavy rain systems around the locations $20^{\circ} \mathrm{N}, 62^{\circ} \mathrm{E} ; 17^{\circ} \mathrm{N}, 84^{\circ} \mathrm{E}$ and $24^{\circ} \mathrm{N}, 88^{\circ} \mathrm{E}$ along with multiple scattered systems (Figure $6 a$ ). The developed technique was able to detect rainfall associated with these rainy systems. Convective rainfall system around $20^{\circ} \mathrm{N}$, $62^{\circ} \mathrm{E}$ showed accumulated rainfall $(3-\mathrm{h})$ in the range 20-65 mm, while system around $17^{\circ} \mathrm{N}, 84^{\circ} \mathrm{E}$ exhibited maximum rainfall of about $90 \mathrm{~mm}$.

The developed technique was validated against ISRO AWS rain-gauge observations during rainy spells from $\mathrm{SW}$ monsoon season at $0.25^{\circ}$ grid box.

For this, 874 data points during rainy spells of monsoon 2007 were considered over the region where raingauge density was good. Figure 7 presents the results. All
24 images of hourly rainfall were accumulated to estimate daily rainfall estimates. Figure 7 also shows a good number of rainy pixels with highest rainfall in the range $100-120 \mathrm{~mm} /$ day. Statistical validation with rain gauge showed a CC of 0.71, RMSE of $17.23 \mathrm{~mm} /$ day, POD of 0.96, FAR of 0.053 and skill score of 0.09 . It infers that this technique retrieves rainfall with a good accuracy over India and nearby regions. Rainfall estimated from Mishra et al. ${ }^{1}$ was also compared with DWR rainfall estimates.

Figure 8 shows comparison of rainfall from Mishra et $a l .{ }^{1}$ with that from DWR for a case study on 22 October 2008 at 0000 UTC. Multiple rainy systems can be observed over land, coast and oceanic region with rainfall in the range $(2-16 \mathrm{~mm} / \mathrm{h})$. It can be observed that structure of rainy system as well as rainfall amount from Mishra et al. ${ }^{1}$ are similar to those of DWR observations. However, few disagreements were observed around the location $15.6^{\circ} \mathrm{N}, 80.8^{\circ} \mathrm{E}$, where Radar showed rain systems having rainfall values in the range $6-16 \mathrm{~mm} / \mathrm{h}$. However, this system was not identified by measurements from Mishra et al. ${ }^{1}$. Figure 9 shows validation of results from Mishra et al. ${ }^{1}$ and DWR. For this, 756 data points during several rainy episodes from 2007 and 2008 were selected. Rain rates are hourly accumulated rainfall. Validation of results with DWR revealed a CC of 0.72 , RMSE of $2.66 \mathrm{~mm} / \mathrm{h}$, bias of $-0.5805 \mathrm{~mm} / \mathrm{h}$ and skill score is 0.53 .

The approach adopted by Mishra et al. ${ }^{1}$ offers a useful technique for measuring rainfall over India and adjoining ocean. Mishra et al. ${ }^{1}$ showed good performance in monitoring convective rainfall over the Indian region. However, performance of the technique is less convincing in detecting non-convective rainfall activities. This technique is operational at $\mathrm{SAC}$, Ahmedabad.

Recently, an algorithm has been developed by combining highly accurate precipitation estimates from GPM with Meteosat 7 observations to measure precipitation over India and nearby oceanic region. Rainfall signature 

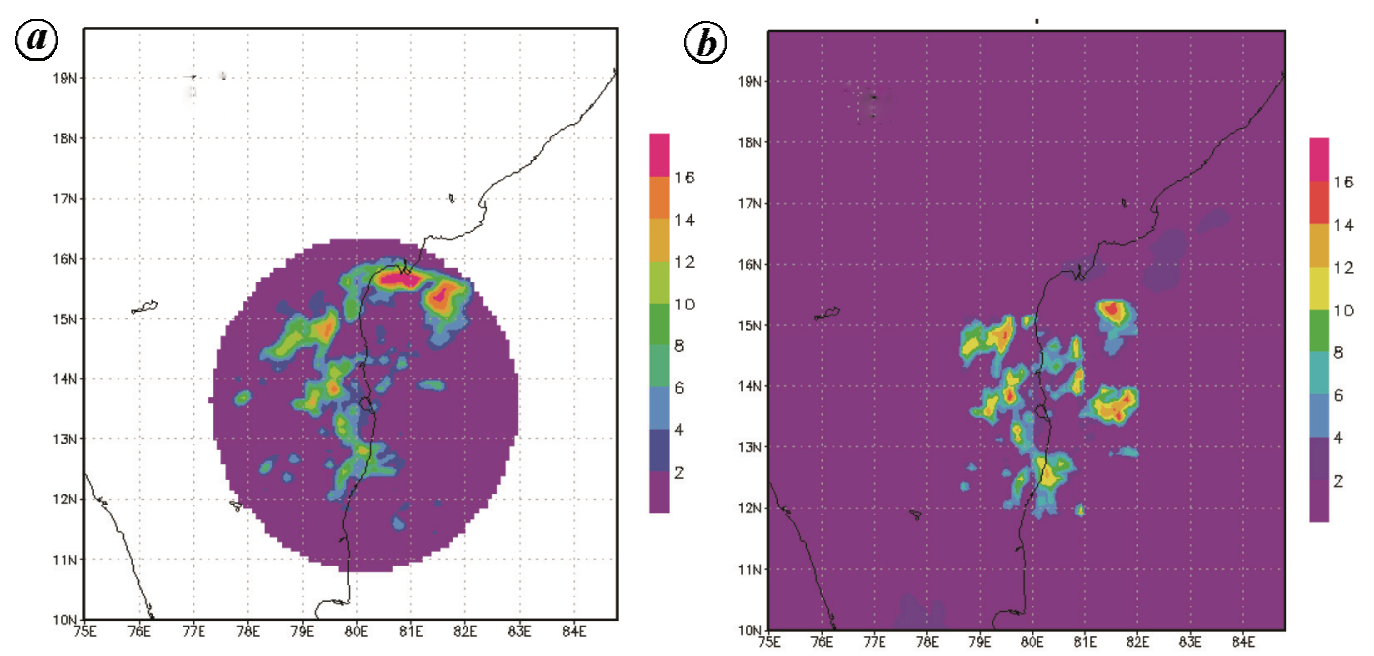

Figure 8. Rainfall rate $(\mathrm{mm} / \mathrm{h})$ on 22 October 2008 at 0000 UTC from (a) DWR and (b) Mishra et al. ${ }^{1}$.

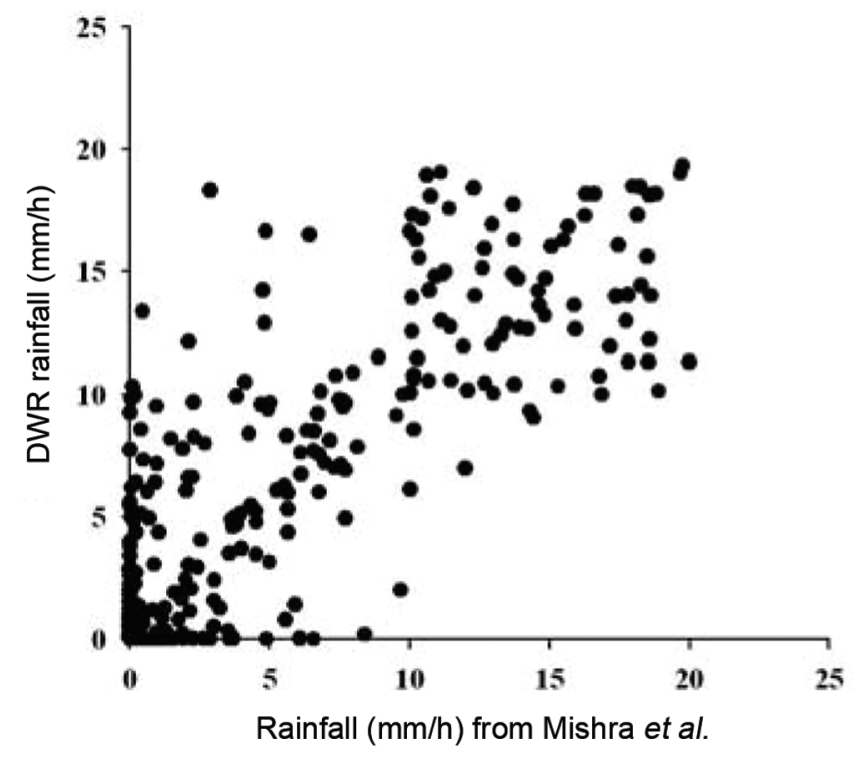

Figure 9. Scatter plot between rainfall estimated by Mishra et al. ${ }^{1}$ and by DWR. (From Mishra et al. ${ }^{1}$; courtesy: AGU JGR).

is derived from Meteosat observations were co-located against rainfall from GPM using the technique devised by Mishra et al. ${ }^{1}$. Rainfall from GPM observations was collocated against rainfall signature using a large database during various rainy seasons. The derived relationship can be used to monitor precipitation over India and adjoining oceanic region. This technique was validated against rain gauges and global precipitation products, including GSMaP, CMORPH, PERSIANN and IMERG. A case study has been discussed to examine the performance of this technique for measuring heavy rainfall over Tambram region $\left(12.933^{\circ} \mathrm{N}, 80.216^{\circ} \mathrm{E}\right)$, Kancheepuram district, Tamil Nadu, during flood events of 2015 (ref. 56). Daily rainfall data from regional meteorological centre, Chennai, have been used for validation purpose. Daily rainfall was estimated by accumulating rainfall in
$24 \mathrm{~h}$ ending 08:30 IST (03:00 GMT) from raingauge observations. Hourly rainfall from IMERG, GSMaP_NRT, CMORPH_RAW, PERSIANN was also accumulated starting at 03:00 GMT of the previous day to $03: 00$ GMT of the present day (Figure 10).

Satellite estimates tend to underestimate heavy rainfall. However, the present technique is closest to rain-gauge measurements.

The rainfall estimation techniques mentioned above were developed for application at coarser spatial resolution (25 km and more). However, for various applications that include nowcasting and flash flood prediction, requirement of a rainfall estimation technique at finer spatial resolution is highly desirable. Mishra ${ }^{57}$ developed technique to estimate rainfall at very fine scale $(5 \mathrm{~km}$ resolution). He used multispectral observation from IR and WV absorption channel at $6.7 \mu \mathrm{m}$ to develop a new rain index (RI). Colder clouds in IR images are more likely to cause rain compared to warm clouds. Observations in WV channel are sensitive to ice concentration in upper-level convective clouds ${ }^{58}$. WV measurements can help detect dry and moist slots. This information is important because rainfall intensity and probability are reduced in dry slot. Rainfall intensity increases within the moist slot and thus probability of rainfall also increases ${ }^{22}$. To derive rain coefficients, brightness temperatures in IR and WV channels were collocated against surface rainfall from PR, and non-rainy brightness temperatures $\left(\mathrm{Tb}_{\mathrm{IR} 0}\right.$ and $T b_{\mathrm{Wv} 0}$ ) were derived as 300 and $250 \mathrm{~K}$.

$\mathrm{TBIR} \geq 300 \mathrm{~K}$ and $\mathrm{TBWV} \geq 250 \mathrm{~K}$ show non-rainy condition. It does not mean that $\mathrm{TBIR}<300 \mathrm{~K}$ and $\mathrm{TbWV}<250 \mathrm{~K}$ indicate rainy condition (it may or may not). Rainy conditions are defined based on match-ups between rain index and rain rate from radar. Rain index $\geq 1.15$ shows rainy condition. Figure 11 shows relationship between rain rate from radar and rain index from Meteosat. 


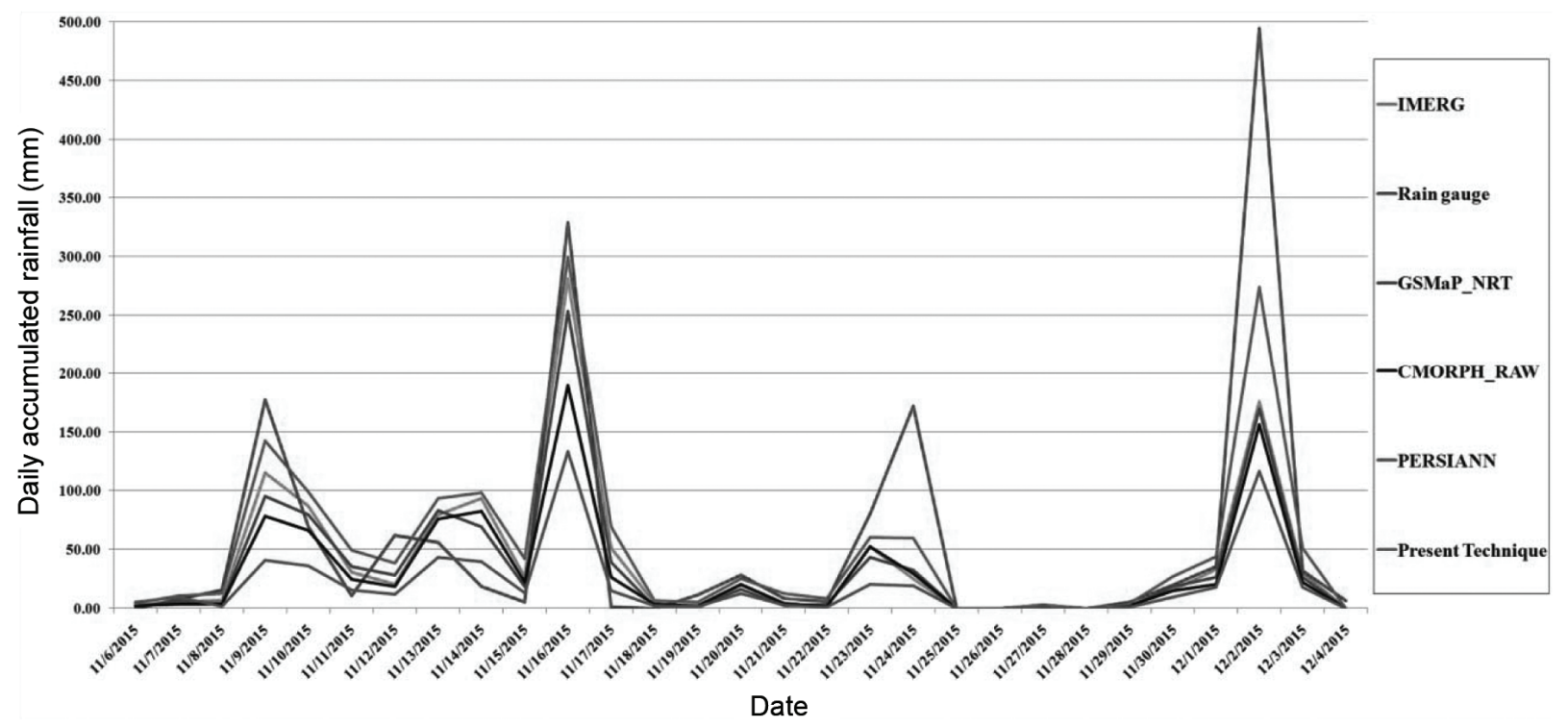

Figure 10. Time series of rainfall over Tambram from rain gauge, IMERG, GSMaP, CMORPH, PERSIANN and the present technique (using GPM data) during November-December 2015.

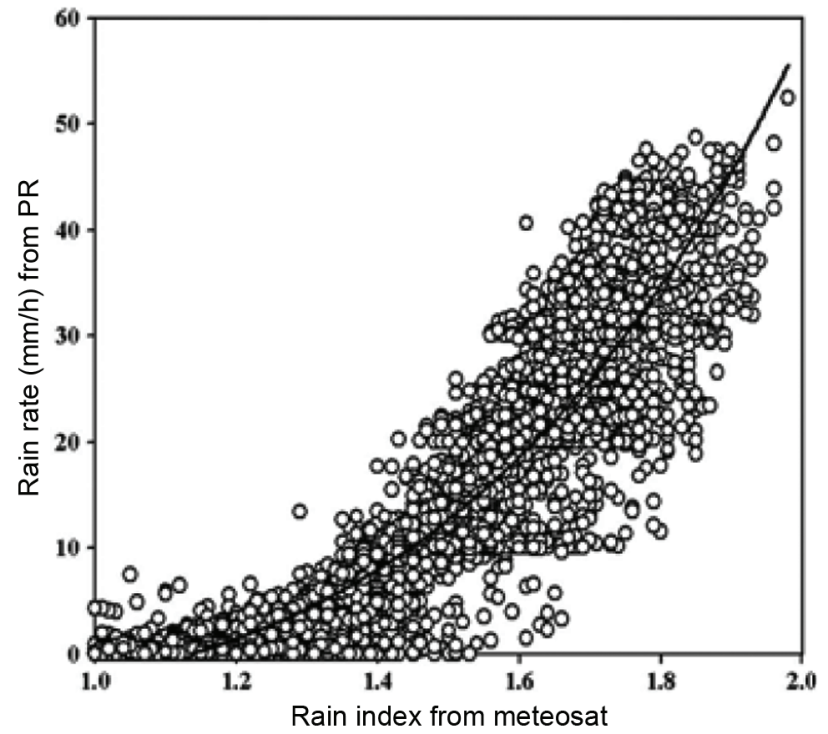

Figure 11. Relationship between RIs from Meteosat and rain measurement from PR (from Mishra ${ }^{9}$; courtesy: IEEE-TGRS).

Coefficients in IR and WV channel measurements were derived as

$$
\begin{aligned}
& \mathrm{IR}_{\text {index }}=\mathrm{Tb}_{\mathrm{IR} 0} / \mathrm{Tb}_{\mathrm{IR}}, \\
& \mathrm{WV}_{\text {index }}=\mathrm{Tb}_{\mathrm{WV} 0} / \mathrm{Tb}_{\mathrm{WV}} .
\end{aligned}
$$

If $\mathrm{Tb}_{\mathrm{IR}} \geq 300$, then $\mathrm{IR}_{\text {index }} \leq 1$ represents a non-rainy condition. If $\mathrm{Tb}_{\mathrm{WV}} \geq 250$, then $\mathrm{WV}_{\text {index }} \leq 1$ refers to a non-rainy condition.
Rain index (RI) was calculated as

$$
\mathrm{RI}=\mathrm{IR}_{\text {index }} \times \mathrm{WV}_{\text {index }} .
$$

Smaller values of $T b_{I R}$ and $T b_{W V}$ give a high value of $R I$, which represents the presence of a very deep convective system.

RI values were plotted against rainfall rate from PR to establish a relationship between the two. The following relationship was established using nonlinear regression analysis:

$$
\operatorname{RR}(\mathrm{mm} / \mathrm{h})=-8.49+\left(2.73 \times \mathrm{RI}^{4.27}\right) .
$$

Equation (12) was used to estimate rainfall at $5 \mathrm{~km}$ spatial resolution. Performance of this technique along with GSMaP and IR-only technique developed by Mishra et $a l{ }^{1}$ was examined against observations from rain gauge. Figure 12 shows the results.

For this purpose, rainfall from rain index-based algorithm, IR-only technique and GSMaP was averaged in the bins of rain-gauge observations. Total number of observations in each bin was kept constant to make the statistical weight uniform. It may be observed from the figure that rain index-based technique outperformed other techniques, especially in case of heavy rain events. Mishra and Srinivasan ${ }^{57}$ used this technique to study heavy rainfall events over Kedarnath on 16 and 17 June 2013 during a flood event. The flood events of Jammu and Kashmir (2014) and Tamil Nadu (2015) were also monitored using this technique ${ }^{56,59}$. Mishra et al. ${ }^{11}$ developed an algorithm for estimating rainfall over a topographically complex region by integrating TRMM observations with Kalpana-1 and applying a cooling index to tackle growth and dissipation of the clouds. Cooling index was derived using 


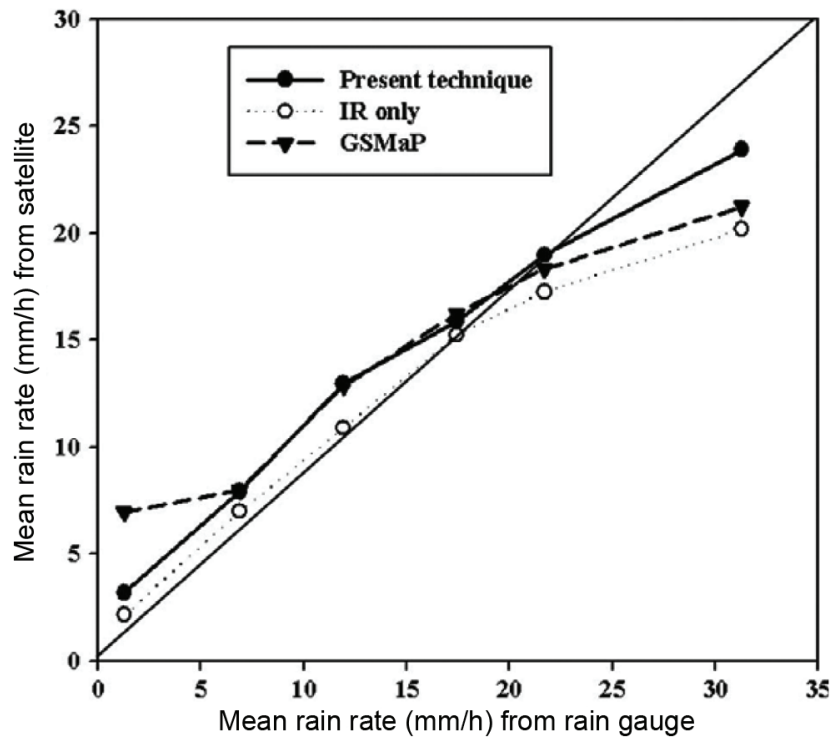

Figure 12. Relationship between binned rainfall from rain gauge and those estimated by Mishra ${ }^{9}$ (rain index-based), IR only (Mishra et al. ${ }^{1}$ ) and GSMaP. (From ref. 9; courtesy: IEEE-TGRS.)

two successive half hourly Kalpana-1 IR brightness temperature data. If cooling index $>0$, pixel is getting warmer (and rainy system is dissipating). If cooling index $<0$, it is getting colder (rainy system is intensifying) and probability of rainfall is more. Validation with rain-gridded rain-gauge products indicates that underestimation of rainfall is minimized by $30 \%$ using the developed approach. Recently Kumar and Varma ${ }^{60}$ used INSAT-3D data to retrieve rainfall using hydro-estimator (HE) technique. This technique estimates rainfall at instantaneous (half-hourly) pixel-scale over land and ocean. It is developed by blending IR measurements with NWP model fields for more precise rain detection and measurement. NWP wind fields laced with tropography are used for correction in rain amount due to orography by application of environmental moisture correction factor. Equilibrium level is identified using NWP-derived temperature and relative humidity profiles, and it is used to make corrections for rain from warm clouds. Compared to IMSRA, HE technique is complex as it includes several parameters to estimate pixel-wise rainfall. Detailed examination of the performance of $\mathrm{HE}$ technique is yet to be performed. A recent study using INSAT-3D data shows that $\mathrm{HE}$ technique is useful for short-range weather forecast ${ }^{60}$. Bushair et al. ${ }^{61}$ monitored rainfall over the Indian region using Kalpana-1-derived IMSRA algorithm. They reported that IMSRA technique has the potential to monitor rainfall during summer monsoon.

\section{Concluding remarks}

Development of rainfall estimation techniques using satellite remote sensing over India and nearby oceanic region is discussed here. Monitoring rainfall from multiple observations suffers from errors due to various factors, including different spatial and temporal resolution which may differ from one another, and the fact that, in a multiple frequency rainfall estimation technique, various parameters are measured with different accura$\operatorname{cies}^{62-67}$.

Presence of additional microwave observations with wide swath and high-frequency channels from GPM and Megha-Tropiques offers an opportunity to augment rainfall estimation technique over the Indian region.

Future scope on the field includes development of regional rainfall signatures using available microwave sensors. Additional high-frequency ice-scattering channels at 157 and $183 \mathrm{GHz}$ will further improve accuracy in rainfall monitoring. Requirement of advanced rainfall estimates from at finer scale over India becomes essential in the context of increased heavy rain events in recent decades $^{65-71}$

1. Mishra, A. K., Gairola, R. M., Varma, A. K. and Agarwal, V. K., Remote sensing of precipitation over Indian land and oceanic regions by synergistic use of multi-satellite sensors. J. Geophys. Res., 2010, 115, D08106, doi:10.1029/2009JD012157.

2. Gairola, R. M., Varma, A. K. and Agarwal, V. K., Rainfall estimation using spaceborne microwave radar and radiometric measurements. Mausam, 2003, 54(1), 89-106.

3. Huffman, G. J. et al., The TRMM multisatellite precipitation analysis (TMPA): quasi-global, multiyear, combined-sensor precipitation estimates at fine scales. J. Hydrometeorol., 2007, 8, 3855.

4. Kubota, T. et al., Global precipitation map using satellite-borne microwave radiometers by the GSMaP project: production and validation. IEEE Trans. Geosci. Remote Sensing, 2007, 45(7), 2259-2274.

5. Joyce, R. J., Janowiak, J. E., Arkin, P. A. and Xie, P., CMORPH: A method that produces global precipitation estimates from passive microwave and infrared data at high spatial and temporal resolution. J. Hydrometeorol., 2004, 5, 487-503.

6. Sorooshian, S., Hsu, K. L., Gao, X., Gupta, H. V., Imam, B. and Braithwaite, D., Evaluation of PERSIANN system satellite-based estimates of tropical rainfall. Bull. Am. Meteorol. Soc., 2000, 81, 2035-2046.

7. Scofield, R. A. and Kuligowski, R. J., Status and outlook of operational satellite precipitation algorithms for extreme-precipitation events. Weather Forecast., 2003, 18, 1037-1051.

8. Huffman, G. J. et al., NASA Global Precipitation Measurement (GPM) Integrated Multi-satellitE Retrievals for GPM (IMERG), Algorithm Theoretical Basis Document (ATBD) Version 4.5, NASA, 2015.

9. Mishra, A. K., A new technique to estimate precipitation at fine scale using multi-frequency satellite observations over Indian land and oceanic regions. IEEE Trans. Geosci. Remote Sensing, 2013, 51(7), 4349-4358; doi.10.1109/TGRS.2012.2226733.

10. Prakash, S., Sathiyamoorthy, V., Mahesh, C. and Gairola, R. M., An evaluation of high resolution multisatellite rainfall products over the Indian monsoon region. Int. J. Remote Sensing, 2014, 35(9), 3018-3035; doi:10.1080/01431161.2014.894661.

11. Mishra, A. K., Gairola, R. M., Varma, A. K. and Agarwal, V. K., Study of intense heavy rainfall events over India using KALPANA-IR and TRMM-precipitation radar observations. Curr. Sci., 2009, 9(5), 689-695. 
12. Martin, D. W. and Scherer, W. D., Review of satellite rainfall estimation methods. Bull. Am. Meteorol. Soc., 1973, 54, 661674.

13. Arkin, P. A., The relationship between fractional coverage of high cloud and rainfall accumulations during GATE over the B-scale array. Monthly Weather Rev., 1979, 106, 1153-1171.

14. Arkin, P. A. and Meisner, B. N., The relationship between largescale convective rainfall and cold cloud over the Western Hemisphere during 1982-84. Monthly Weather Rev., 1987, 115, 51-74.

15. Arkin, P. A., Krishna Rao, A. V. R. and Kelkar, R. R., Large-scale precipitation and outgoing longwave radiation from INSAT-1B during the 1986 southwest monsoon season. J. Climate, 1989, 2(6), 619-628.

16. Rao, A. V. R. K., Kelkar, R. R. and Arkin, P. A., Estimation of precipitation and outgoing longwave radiation from INSAT-1B radiance data. Mausam, 1989, 40, 123-130.

17. Bhandari, S. M. and Varma, A. K., Estimation of large scale monthly rainfall over Indian region using minimal INSAT-VHRR data. Int. J. Remote Sensing, 1995, 16(11), 2023-2030.

18. Roy Bhowmik, S. K. and Sud, A. M., Seasonal and spatial characteristic of QPE errors over Indian region. Mausam, 2003, 54, 653658

19. Nath, S., Mitra, A. K. and Roy Bhowmik, S. K., Improving the quality of INSAT derived quantitative precipitation estimates using neural network method. Geofizika, 2008, 25(1), 41-51.

20. Durai, V. R., Roy Bhowmik, S. K. and Mukhopadhyay, B., Evaluation of Indian summer monsoon rainfall features using TRMM and KALPANA-1 satellite derived precipitation and rain gauge observation. Mausam, 2010, 61(3), 317-336

21. Prakash, S., Mahesh, C. and Gairola, R. M., Large scale precipitation estimation using Kalpana-1 IR measurements and its validation using GPCP and GPCC data. Theor. Appl. Climatol., 2011, 106(3-4), 283-293; doi:10.1007/s00704-011-0435-7.

22. Mishra, A. K., Gairola, R. M., Varma, A. K. and Agarwal, V. K. Improved rainfall estimation over the Indian region using satellite infrared technique. Adv. Space Res., 2011, 48, 49-55; doi:10.1016/j.asr.2011.02.016.

23. Vicente G., Scofield, R. A. and Mensel, W. P., The operational GOES infrared rainfall estimation technique. Bull. Am. Meteorol. Soc., 1998, 79, 1883-1898.

24. Singh, H. and Singh, O. P., Satellite derived precipitation estimates over Indian region during southwest monsoons. J. Indian Geophys. Union, 2013, 17(1), 65-74.

25. Gairola, R. M., Praksh, S., Bushair, M. T. and Pal, P. K., Rainfall estimation from Kalpana-1 satellite data over Indian land and oceanic regions. Curr. Sci., 2014, 107(8), 1275-1282.

26. Spencer, R. W., Goodman, H. M. and Hood, R. E., Precipitation retrieval over land and ocean with the SSM/I: Identification and characteristics of the scattering signal. J. Atmos. Oceanic Technol., 1989, 6, 254-273.

27. Grody, N. C., Classification of snow cover and precipitation using the special sensor microwave/imager $(\mathrm{SSM} / \mathrm{I})$. J. Geophys. Res., 1991, 96, 7423-7435.

28. Liu, G. and Curry, J. A., Retrieval of precipitation from satellite microwave measurements using both emission and scattering. J. Geophys. Res., 1992, 97, 9959-9974.

29. Negri, A. J., Adler, R. F., Nelkin, E. J. and Huffman, G. J., Regional rainfall climatologies derived from Special Sensor Microwave Imager (SSM/I) data. Bull. Am. Meteorol. Soc., 1994, 75, 1165-1182.

30. Barrett, E. C. and Bellerby, T. J., The application of satellite infrared and passive microwave rainfall estimation techniques to Japan: Results from the first GPCP algorithm intercomparison project. Meteor. Mag., 1992, 121, 34-46.

31. Ferraro, R. R., Grody, N. C., Alishouse, J. C. and Marks, G. F., The calibration of SSM/I scattering index for rain rate retrievals using RADAP-II and AMeDAS radar data, Preprints. In Sixth
Conference on Satellite Meteorology and Oceanography, American Meteorological Society, Atlanta, GA, 1992, pp. 290-295.

32. Mishra, A. K., Gairola, R. M., Varma, A. K., Sarkar, A. and Agarwal, V. K., Rainfall Retrieval over Indian land and oceanic regions from SSM/I microwave data. Adv. Space Res., 2009, 44, 815-823; doi:10.1016/j.asr.2009.05.010.01

33. Mishra, A. K., Estimation of heavy rainfall during cyclonic storms from microwave observations using nonlinear approach over Indian ocean. Natural Hazards, 2012, 63, 673-683, doi: 10.1007/s11069-012-0179-4.

34. Janowiak, J. E., Arkin, P. A., Xie, P., Morrey, M. L. and Ligates, D. R., An examination of the east pacific ITCZ rainfall distribution. J. Climate, 1995, 8, 2810-2823.

35. Wilheit, T. T., A model for the microwave emissivity of the ocean's surface as a function of wind speed. IEEE Trans. Geosci. Electron., 1979, 17(4), 244-249.

36. Ferraro, R. R. and Marks, G. F., The development of SSM/I rain rate retrieval algorithms using ground based radar measurements. J. Atmos. Oceanic Technol., 1995, 12, 755-770.

37. Noh, Y.-J. and Liu, G., Satellite and aircraft observations of snowfall signature at microwave frequencies. Riv. Ital. Telerilevamento, 2004, 30, 101-118.

38. Kumar, P. and Varma, A. K., Assimilation of INSAT-3D hydro-estimator method retrieved rainfall for short-range weather prediction. Quart. J. R. Meteorol. Soc., 2016; doi:10.1002/ qj.2929.

39. Gohil, B. S., Gairola, R. M., Mathur, A. K., Varma, A. K., Mahesh, C., Gangwar, R. K. and Pal, P. K., Algorithms for retrieving geophysical parameters from the MADRAS and SAPHIR sensors of the Megha-Tropiques satellite: Indian scenario. Quart. J. R. Meteorol. Soc., 2013, 139(673), 954-963.

40. Balaji, C., Krishnamoorthy, C. and Chandrasekar, R., On the possibility of retrieving near-surface rain rate from the microwave sounder SAPHIR of the Megha-Tropiques mission. Curr. Sci., 2014, 106(4), 587.

41. Jobard, I. and Desbois, M., Satellite estimation of the tropical precipitation using the Meteosat and SSM/I data. Atmos. Res., 1994, 34, 285-298.

42. Adler, R. F., Huffman, G. J. and Keehn, P. R., Global rain estimates from microwave adjusted geosynchronous IR data. Remote Sensing Rev., 1994, 11, 125-135.

43. Gairola, R. M. and Krishnamurti, T. N., Rain rates based on SSM/I, OLR and raingauge data sets. Meteorol. Atmos. Phys., 1992, 50(4), 165-174.

44. Roy Bhowmik, S. K. and Das, A. K., Rainfall analysis for Indian monsoon region using the merged rain gauge observations and satellite estimates: Evaluation of monsoon rainfall features. J. Earth Syst. Sci., 2007, 116(3), 187-198.

45. Mitra, A. K., Bohra, A. K., Rajeevan, M. N. and Krishnamurti, T. N., Daily Indian precipitation analysis formed from a merge of rain-gauge data with the TRMM TMPA satellite-derived rainfall estimates. J. Meteorol. Soc. Japan. Ser. II, 2009, 87, 265-279.

46. Krishnamurti, T. N., Mishra, A. K., Simon, A. and Yatagai, A., Use of a dense rain-gauge network over India for improving blended TRMM products and downscaled weather models. J. Meteorol. Soc. Japan. Ser. II, 2009, 87, 393-412.

47. Gairola, R. M., Mishra, A., Prakash, S. and Mahesh, C., Development of INSAT multi-spectral rainfall algorithm (IMSRA) for monitoring rainfall events over India using KALPANA-IR and TRMM-precipitation radar observations. Scientific Report, 2010, SAC/EPSA/AOSG/INSAT/SR-39/2010.

48. Prakash, S., Mahesh, C., Gairola, R. M. and Pal, P. K., Estimation of Indian summer monsoon rainfall using Kalpana-1 VHRR data and its validation using rain gauge and GPCP data. Meteorol. Atmos. Phys., 2010, 110(1-2), 45-57.

49. Roy, S. S., Saha, S. B., Fatima, H., Bhowmik, S. R. and Kundu, P. K., Evaluation of short-period rainfall estimates from Kalpana-1 


\section{REVIEW ARTICLES}

satellite using MET software. J. Earth Syst. Sci., 2012, 121(5), 1113-1123.

50. Das, S. K., Deb, S. K., Kishtawal, C. M. and Pal, P. K., Seasonal prediction of Indian summer monsoon: Sensitivity to persistent SST. J. Earth Syst. Sci., 2013, 122(5), 1183-1193.

51. Gairola, R. M., Prakash, S. and Pal, P. K., Improved rainfall estimation over the Indian monsoon region by synergistic use of Kalpana-1 and rain gauge data. Atmósfera, 2015, 28(1), 51-61.

52. Roca Remy, M., Viollier, L. Picon and Desbois, M., A multisatellite analysis of deep convection and its moist environment over the Indian Ocean during the winter monsoon. J. Geophys. Res., 2002, 107, D19; doi:10.1029/2000JD000040.

53. Barrett, E. C. and Martin, D. W., The Use of Satellite Data in Rainfall Monitoring, Academic Press, London, 1981, p. 340.

54. Laughlin, C. R., On the effect of temporal sampling on the observation of mean rainfall. Precipitation Measurements from Space (Workshop report) (eds Atlas, D. and Thiele, O. W.), NASA/ GSFC, 1981, pp. D59-D66.

55. Varma, A. K., Gairola, R. M., Pokhrel, S., Gohil, B. S., Mathur, A. K. and Agarwal, V. K., Rain Rate Measurements over global oceans from IRS-P4 MSMR. Proc. Indian Acad. Sci. Earth Planet. Sci., 2002, 111, 257-266.

56. Mishra, A. K., Monitoring Tamil Nadu flood of 2015 using satellite remote sensing. Natural Hazards, 2016, 82(2), 1431-1434.

57. Mishra, A. K. and Srinivasan, J., Did a cloud burst occur in Kedarnath during 16 and 17 June 2013? Curr. Sci., 2013, 105(10), 1351-1352.

58. Wu, R. and Weinmann, J. A., Microwave radiances from precipitation clouds containing a spherical ice, combined phase, and liquid hydrometeors. J. Geophys. Res., 1984, 89(D5), 7170-7178.

59. Mishra, A. K., A study on the occurrence of flood events over Jammu and Kashmir during September 2014 using satellite remote sensing. Natural Hazards, 2015, 78(2), 1463-1467.

60. Kumar, R., Gairola, R. M., Mishra, A., Varma, A. K. and Das, I. M. L., Evaluation of precipitation features in high-frequency $\mathrm{SSM} / \mathrm{I}$ measurements over Indian land and oceanic regions. IEEE Geosci. Remote Sensing Lett., 2009, 6(3), 373-377.

61. Bushair, M. T., Prakash, S., Patel, S. and Gairola, R. M., Assessment of Kalpana-1 rainfall product over Indian Meteorological Sub-Divisions during the summer monsoon season. J. Indian Soc. Remote Sensing, 2016, 44(1), 67-76.

62. Rafiq, M., Mishra, A. K., Panda, J. and Sharma, S. K., Monitoring convective clouds over India and nearby regions using multispectral satellite observations. In Proceedings of International
Conference on Remote Sensing for Disaster Management, Springer, Cham, 2019, pp. 51-60

63. Rafiq, M. and Mishra, A. K., Remote sensing of near-real-time heavy precipitation using observations from GPM and MFG over India and nearby oceanic regions. In Multidisciplinary Digital Publishing Institute Proceedings, 2018, vol. 2, No. 7, p. 327.

64. Mishra, A. and Rafiq, M., Towards combining GPM and MFG observations to monitor near real time heavy precipitation at fine scale over India and nearby oceanic regions. Dyn. Atmos. Oceans, 2017, 80, 62-74

65. Rajeevan, M., Bhate, J. and Jaswal, A. K., Analysis of variability and trends of extreme rainfall events over India using 104 years of gridded daily rainfall data. Geophys. Res. Lett., 2008, 35(18).

66. Mishra, A. and Liu, S. C., Changes in precipitation pattern and risk of drought over India in the context of global warming. $J$. Geophys. Res.: Atmos., 2014, 119(13), 7833-7841.

67. Goswami, B. N., Venugopal, V., Sengupta, D., Madhusoodanan, M. S. and Xavier, P. K., Increasing trend of extreme rain events over India in a warming environment. Science, 2006, 314(5804), 1442-1445.

68. Mishra, A., Chandra, S., Rafiq, M., Sivarajan, N. and Santhanam, K., An observational study of the Kanchipuram flood during the northeast monsoon season in 2015. Weather, 2018), 73(9), 300301.

69. Mishra, A. K., Nagaraju, V., Rafiq, M. and Chandra, S., Evidence of links between regional climate change and precipitation extremes over India. Weather, https://doi.org/10.1002/wea.3259.

70. Rafiq, M. and Mishra, A. K., A study of heavy snowfall in Kashmir, India in January 2017. Weather, 2018, 73(1), 15-17.

71. Rafiq, M. et al., Modelling Chorabari Lake outburst flood, Kedarnath, India. J. Mountain Sci., 2018, 15; https://doi.org/10.1007/ s11629-018-4972-8.

ACKNOWLEDGEMENTS. Funding support from ISRO under grant no. B. 19012/174/2016-Sec.2 and CSIR under grant no. 24(0350)/17/ EMR-II is acknowledged.

Received 7 March 2017; revised accepted 30 October 2018

doi: $10.18520 / \mathrm{cs} / \mathrm{v} 116 / \mathrm{i} 1 / 56-68$ 